The International Journal of Flexible Manufacturing Systems, 5 (1993): 301-323

(C) 1993 Kluwer Academic Publishers, Boston. Manufactured in The Netherlands.

\title{
Experimental Investigation of an FMS Due-date Scheduling Problem: Evaluation of Machine and AGV Scheduling Rules
}

\author{
IHSAN SABUNCUOGLU \\ Department of Industrial Engineering, Bilkent University, Ankara, Turkey 06533 \\ DON L. HOMMERTZHEIM \\ Department of Industrial Engineering, Wichita State University, Wichita, KS 67208
}

\begin{abstract}
Although extensive research has been conducted to solve design and operational problems of automated manufacturing systems, many of the problems still remain unsolved. This article investigates the scheduling problems of flexible manufacturing systems (FMSs). Specifically, the relative performances of machine and automated guided vehicle (AGV) scheduling rules are analyzed against various due-date criteria. First, the relevant literature is briefly reviewed, and then the rules are tested under different experimental conditions by using a simulation model of an FMS. The sensitivity to AGV workload, buffer capacity, and processing-time distribution is also investigated to assess the robustness of the scheduling rules.
\end{abstract}

Key Words: flexible manufacturing systems, automated guided vehicles, scheduling, dispatching, simulation.

\section{Introduction}

Today, flexible manufacturing systems (FMSs) seem to be a very promising technology, as they provide flexibility which is essential for many manufacturing companies to stay competitive in a highly dynamic and changing manufacturing environment. Existing FMS implementations have already demonstrated a number of benefits in terms of cost reductions, increased utilizations, reduced work-in-process levels, etc. However, there are a number of problems faced during the life cycle of an FMS. These problems are classified by Stecke (1985) into: design, planning, scheduling, and control problems. This article is primarily concerned with scheduling problems of FMSs.

In general, scheduling problems of FMSs are more difficult than traditional job-shop problems due to considerations of the additional resource constraints (i.e., materials handling, limited in-process buffer spaces, etc.). Furthermore, the dynamic nature of an FMS amplifies these problems. In the literature, there are also a number of studies and proposed solution approaches ranging from analytical techniques to simulation and artificial intelligence (Raman, Talbot and Rachamadugu 1986; Seidmann and Tenenbaum 1986; Kusiak and Chen 1988; Hutchinson, Leong, Synder and Ward 1989; Sabuncuoglu and Hommertzheim $1989 \mathrm{~b}, 1992 \mathrm{~b}$ ). While the research in each direction is necessary for better understanding and better solution of FMS problems, this article focuses on simulation-based 
experimental studies of the FMS scheduling problem. Specifically, FMS due-date scheduling rules are compared by using several due-date related criteria under a wide variety of experimental conditions.

The benefit of this research can be summarized as follows. First of all, scheduling rules are widely used in practice for situations ranging from direct use as scheduling heuristics to indirect use as a part of knowledge-bases of expert systems or static-schedule-generation schemes. However, there is only nominal information available about their individual performance against due-date related criteria. In these respects, the results of this research will aid in defining their effects. Second, in most of the simulation studies of FMS scheduling rules, only machines are considered, while the materials handling aspect of FMSs are ignored. Since AGV rules are also considered in this research, the results of this article can provide a better insight into the impact of an AGV system on the FMS scheduling problem.

The remainder of the article is organized as follows. In Section 2, a survey of relevant literature is presented. This is followed in Section 3 by a presentation of system considerations, a description of the simulation model used, and underlying assumptions. In Section 4 , the relative performances of scheduling rules are measured under a wide variety of conditions. Finally, concluding remarks are made in section 5.

\section{Literature review: scheduling criteria and rules with due-dates}

As reported by Smith, Ramesh, Dudek and Blair (1986), meeting due-dates is one of the most important scheduling criteria used in various existing FMS implementations. However, it is very difficult to find a compromise of due-date performances from the wide variety of measures used in industry. In general, the FMS scheduling problem is multi-objective, and the selection of these measures depends on various factors, such as characteristics of parts, lead-time considerations, as well as the overall objectives of a company.

Besides the problem of selecting an appropriate performance measure, there are also additional complications due to setting appropriate due-dates for the parts. When due-dates are dictated by the customer, the approach involved is called exogenous due-date assignment. At other times, when due-dates are totally under the control of a company, which sets them based on expected completion time of parts, the setting is called endogenous due-date assignment.

In general, the due-date of a part is determined by allocating a reasonable amount of time (a flow allowance) for the performance of various associated activities (i.e., processing, materials handling, waiting, etc.). This amount of budgeted time is also an indicator of the level of due-date tightness. There are various approaches to setting due-dates ranging from analytical algorithms to simple rules (Smith and Seidmann 1983). In this article, both endogenous and exogenous due-date assignment procedures are considered.

Endogenous due-date assignment rules were extensively investigated in job-shop environments by Kanet and Christy (1989); Baker (1984); and Baker and Kanet (1983, 1984). Sabuncuoglu and Hommertzheim (1990) also reviewed due-date assignments in the context of an FMS and found the TWK (total work content) due-date assignment rule to be the best rule. Their results were consistent with the findings of previous job-shop studies. 
Once the due-date is set, it represents the part-based due-date. Since each part may require several operations provided by different machines, operation-based due-dates can also be determined by allocating the original flow allowance among the operations associated with the part. In the scheduling literature, operation-based due-date assignment was investigated by several researchers (Baker 1984; Baker and Kanet 1983; Kanet and Hayya 1982). Their results indicate that the operation-based due-date assignment rules produce better due-date performances than the part-based versions.

After the due-dates are set, they represent the planned departure date of the parts from the system. Thus, the objective of the scheduling system is to find the best production schedule to process all parts so as to meet these dates. There are a number of scheduling rules that attempt to achieve this goal. These scheduling rules use priorities calculated from due-date information. Thus, the parts are scheduled on the machines based on these urgency parameters. Most of them have been tested in job-shop environments (Baker 1984; Baker and Kanet 1983; Conway, Maxwell and Miller 1967). The results are mixed; however, there is an indication that the operation-based, due-date rules perform better than the part-based versions.

In the FMS scheduling literature, Montazeri and Wassenhove (1989) investigated the performance of several slack-based, due-date rules. Their conclusion is that S/OPN (Smallest Remaining Slack per Operation) performs better than other due-date scheduling rules. Choi and Malstrom (1988) also tested due-date scheduling rules in an FMS. Their limited supply is based on a comparison of several job-shop scheduling rules using a physical simulator. The results they obtained indicate that SLK (Slack) is the preferred scheduling rule based on various due-date performance measures they employed. However, in their study, the AGV system was not modeled. Furthermore, due-date assignment was not explicitly described. Han and McGinnis (1989) have also investigated the FMS scheduling problem. The static version of the AGV routing problem was identified as a one-machine, due-date problem. However, throughput was measured as the performance criterion in their study.

In this article, machine and material handling aspects of FMSs are considered. Scheduling rules are grouped into: (1) machine scheduling and (2) AGV scheduling. The machine scheduling rules are those which are used to select the next part from the input queue upon the availability of the correct machine. AGV rules are used to select the next machine and part to be served upon the availability of an AGV. Machine scheduling rules were selected form the recent FMS and job-shop literature and are listed in table 1. Their mathematical definitions can be found in table 2. The AGV scheduling rules are given in table 3. FCFS (First-Come, First-Served) has the ability to complement the machine scheduling rules by serving a machine with the earliest part completion. The LQS (Largest Queue Size) rule uses information on queue level. This rule was found to be the best AGV rule against the mean flow-time criterion in the previous studies (Sabuncuoglu and Hommertzhiem 1989a, 1992a). Since none of the AGV rules (table 3) utilize due-date information, machine duedate scheduling rules (table 1) are also used as the AGV rules in some of the experiments. The following notation is used in defining the scheduling rules:

$\mathrm{i}=$ part index

j $=$ operation index

$\mathrm{t}=$ time at which the scheduling decision is being made 
Table 1. Due-date scheduling rules for machine scheduling.

\begin{tabular}{ll}
\hline Symbol & \multicolumn{1}{l}{ Description of the Rule } \\
\hline I) Part-based, due-date rules \\
EDD & Earliest Due-Date \\
MDD & Smallest Modified Due-Date \\
SLK & Smallest Remaining Slack \\
A/OPN & Smallest Remaining Allowance per Operation \\
S/OPN & Smallest Remaining Slack per Operation \\
II) Operation-based, due date rules \\
ODD & Earliest Operation Due-Date \\
MOD & Smallest Modified Operation Due-Date \\
OST & Smallest Remaining Operation Slack Time \\
\hline
\end{tabular}

Table 2. Mathematical definitions of scheduling rules.

\begin{tabular}{ll}
\hline EDD : & $D_{\mathbf{i}}$ \\
MDD : & $\max \left(D_{i}, t+P_{j}\right)$ \\
SLK : & $D_{i}-t-P_{j}$ \\
A/OPN : & $\left(D_{i}-t\right) / n_{i}$ \\
S/OPN : & $\left(D_{i}-t-P_{j}\right) / n_{i}$ \\
ODD : & $d_{i, j}$ \\
MOD : & $\max \left(d_{i, j}, t+p_{i, j}\right)$ \\
OST : & $d_{i, j}-t-p_{i, j}$ \\
\hline
\end{tabular}

Table 3. AGV scheduling rules.

\begin{tabular}{ll}
\hline FCFS & (First-Come, First-Served) \\
LQS & (Largest Queue Size, including incoming \\
& and outgoing parts) \\
\hline
\end{tabular}

$\mathrm{D}_{\mathrm{i}}=$ due-date of part $\mathrm{i}$

$d_{i, j}=$ due-date of part $i$ for operation $j$

$\mathbf{R}_{\mathbf{i}}=$ ready time or arrival time of part $i$

$c_{i}=$ completion time of part $i$

$\mathbf{k}=$ allowance factor or measure of due-date tightness

$n_{i}=$ remaining number of operations of part $i$

$p_{i, j}=$ operation time for $j$ th operation of part $i$

$P_{i}=$ total operation time of part $i$

$F_{i}=C_{i}-R_{i}$ (flow time of part $\mathbf{i}$ )

$L_{i}=C_{i}-D_{i}$ (lateness of part $i$ )

$\mathrm{T}_{\mathrm{i}}=\max \left\{0, \mathrm{C}_{\mathrm{i}}-\mathrm{D}_{\mathrm{i}}\right\}$ (tardiness of part $\mathrm{i}$ ) 
Due-dates are assigned by the TWK rule, because this rule has been found to be quite robust in previous studies (Kanet and Christy 1989; Sabuncuoglu and Hommertzheim 1990). By using this rule, due-dates were determined as shown below:

$$
\begin{aligned}
& D_{i}=R_{i}+k * P_{i} \\
& d_{i, j}=d_{i, j-1}+k * p_{i, j}
\end{aligned}
$$

\section{System considerations, simulation model, and experimental conditions}

Figure 1 shows the layout of the hypothetical FMS studied in this research. In this system, there are six machining centers, one inspection station, one washing station, and one input/output carousel. Each machining center has a finite input/output buffer space in which parts can wait before and after an operation. There are also two central buffer areas at which parts are temporarily stored to prevent system locking. Parts are transferred in the system by an AGV system. Each AGV moves a part between the machines along a predetermined and unidirectional path. Upon completion of a part transfer, an idle AGV either returns to the staging area or stays at the same station for the next journey, depending upon the current operating policy. As far as the link between the workstations and the AGVs is concerned, a direct-access, part-retrieval design is considered to be operational. Therefore, any part from the queue can be retrieved regardless of its position in the queue. A simulation model of the FMS described above was developed in SIMAN (Pegden 1985).

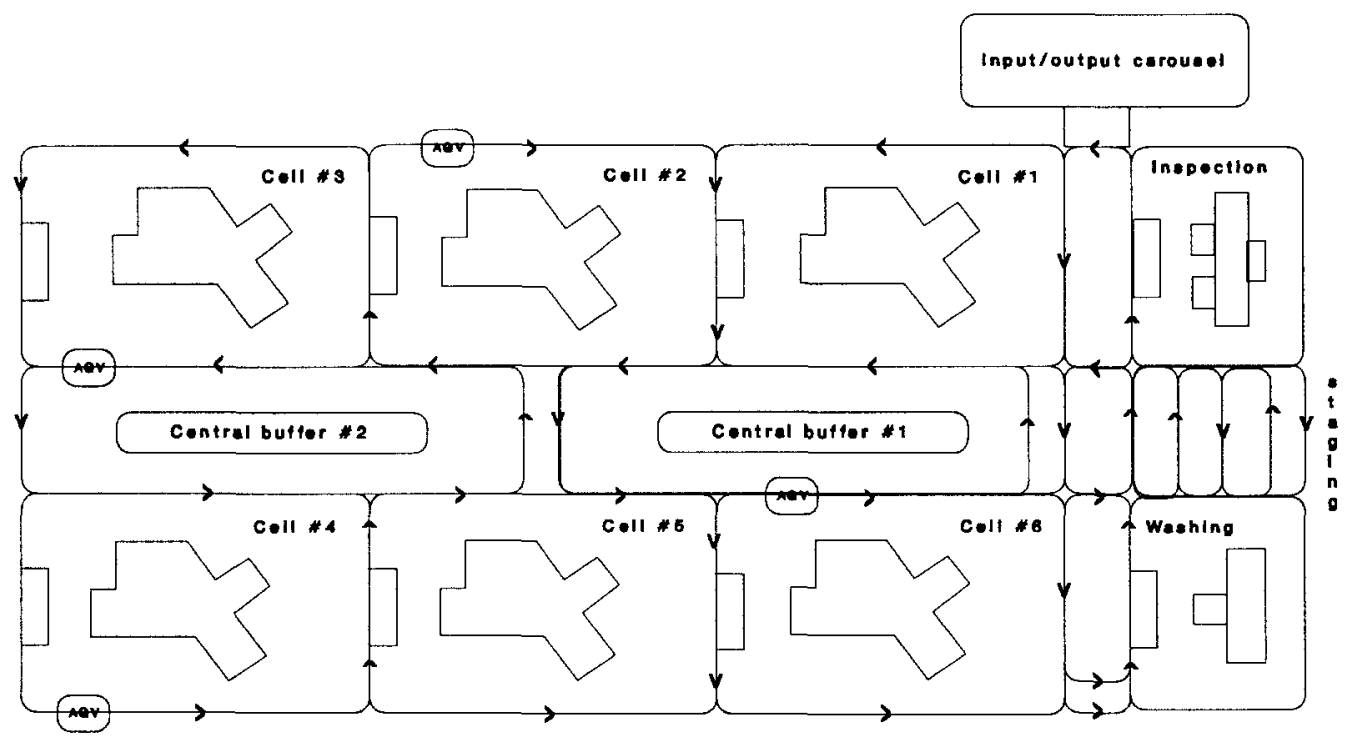

Figure 1. Schematic view of an FMS. 
Parts arrive according to the Poisson process. It is assumed that all design and planning (i.e., allocation of tools, process plans, and routing of parts) issues, as suggested by Stecke (1985), have already been resolved. Each part is processed by a series of machines. The number of operations is determined by a discrete, uniform distribution between one and six. The arriving parts are held in a load/unload area (or carousel) and are allowed into the system on a FCFS basis, as long as both an AGV and one queue space at the respective machines are available. The machine assignment is random, and no part is allowed to visit the same machine more than once. Besides the machines, all of the parts visit the washing station. However, only $\mathbf{5 0 \%}$ of the parts are inspected. Finally, two AGVs are employed in the model.

The scheduling rules are tested under the following experimental conditions. They are as follows:

- different distribution type and parameters for processing times (i.e., exponential and normal distributions)

- varying machine and AGV load levels

- different queue capacities and AGV speeds

- varying levels of due-date allowances.

For the operation-time distribution, both exponential and normal distributions are used. Since the normal distribution is one of the distributions for which the variance is independent of the mean, it allows the analyst to control the variability in the system. In the experiments, only positive values are considered for the normally distributed processing times.

A common random-number, variance-reduction technique was implemented to compare the rules under identical conditions and to reduce the simulation run length. Furthermore, in order to obtain consistent samples from the simulation model, the parts were numbered in the order of their arrival, and the statistics were updated for those numbered parts. Based on pilot runs, which determined the transient period, statistics for the first 300 parts were discarded and samples collected for only the parts numbered between 301 and 3300.

\section{Simulation results}

The due-date performance of the eight due-date scheduling rules are analyzed under different experimental conditions. First, the rules are compared using the normally distributed processing times. Then the experiments are repeated using the exponential distribution.

\subsection{Analysis of the due-date scheduling rules using normally distributed processing times}

The FMS model was simulated at varying allowance levels (or due-date tightness) ranging from very tight $(k=3)$ to very loose $(k=6)$. In the experiments, due-date scheduling rules (given in table 1) were used as the machine-scheduling rules. The average utilization rates of the machines and the AGV system were approximately 85 and $87.5 \%$, respectively. Although the primary performance measure was mean tardiness (MT), other due-date 
performances were also measured. These are: maximum tardiness (TMAX), meanconditional tardiness (MCT), mean lateness (ML), standard deviation of lateness (VL), proportion of tardy parts (PT), and mean flow-time (MF).

Since it is very difficult to investigate the performance of the rules under all possible combinations of these factors (i.e., the combinatorial nature of the problem), changes in the conditions were made one at a time. Thus, in conducting experiments, first the rules were compared under standard (or base) conditions, and then simulation experiments were repeated by varying the conditions. Although some of the results are given in tables, most of the results are summarized in figures, in order to show the behavior of rules at varying conditions.

Figure 2 displays mean-tardiness performances of the eight machine scheduling rules when FCFS was the AGV rule. Table 4 summarizes the results for all due-date performance measures (the minimum values are boldfaced). In general, the results are quite mixed. No single rule dominates other rules. Their performances change as the due-date tightness varies. In conclusion, there is not a single rule which optimizes all due-date performance measures.

The same type of crossover effect can also be observed when LQS was used as the AGV rule (figure 3). Only MOD produces slightly better due-date performance when the duedate is tight $(k=3)$. But, in the rest of the conditions, neither MOD nor the other rules yield superior results. However, it can be noticed that the resulting mean tardiness performance of rules is better, as compared to the previous case. This is because LQS is a better rule than FCFS for minimizing mean flow-time (Sabuncuoglu and Hommertzheim 1992a). Thus, better flow-time performance can also improve due-date performances, especially at tight due-dates.

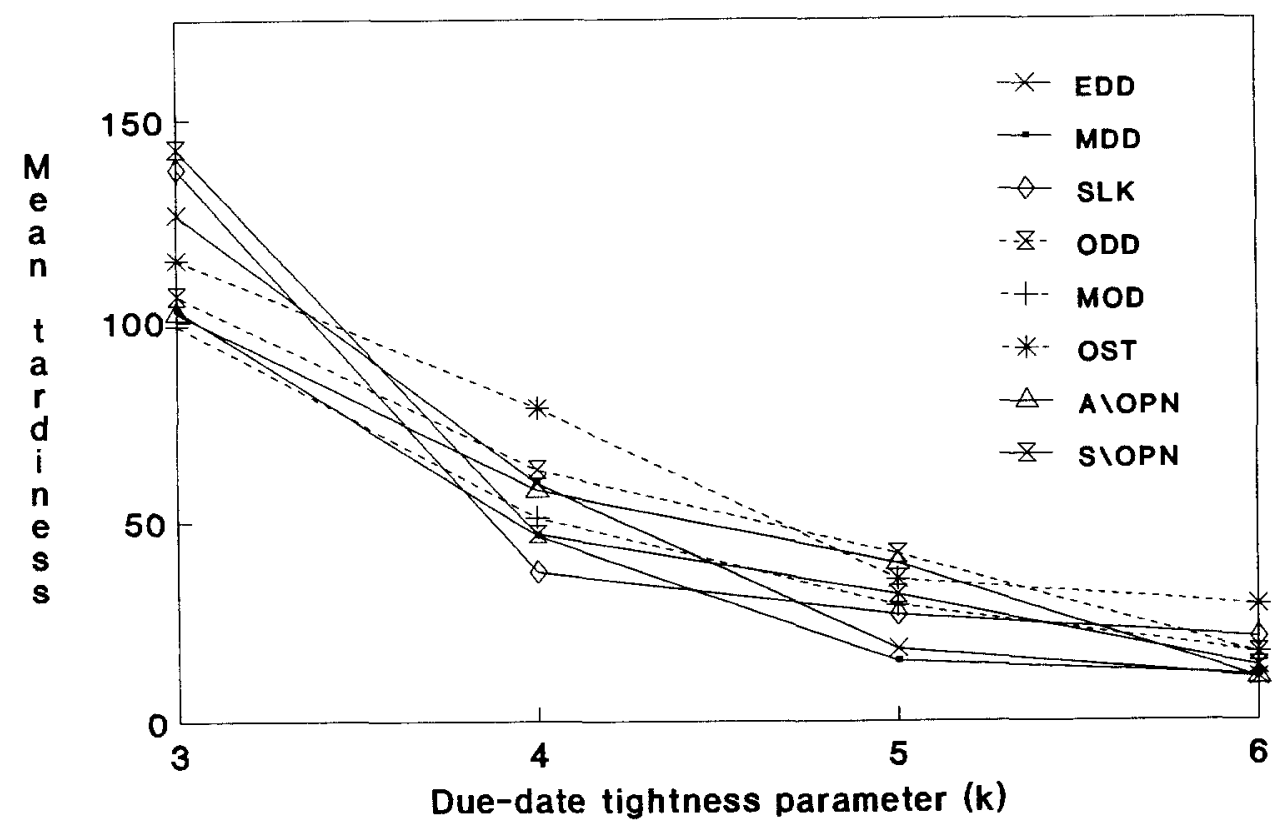

Figure 2. Normal with FCFS rules. 
Table 4. Due-date performance of the scheduling rules at varying due-date tightness, parameter (k) (FCFS is the AGV rule).

\begin{tabular}{|c|c|c|c|c|c|c|c|c|}
\hline & \multirow[b]{2}{*}{ Due-Date Rules } & \multicolumn{7}{|c|}{ Due-Date Measures } \\
\hline & & MT & CMT & TMAX & $\mathrm{PT}(\%)$ & ML & VL & $\mathbf{M F}$ \\
\hline \multirow{8}{*}{$k=3$} & EDD & 126.4 & 169.7 & 1125.2 & 74.6 & 113.7 & 12.5 & 414.7 \\
\hline & MDD & 103.0 & 151.0 & 1822.9 & 68.2 & 88.8 & 13.5 & 389.7 \\
\hline & SLK & 137.8 & 176.7 & 1121.2 & 77.8 & 127.7 & 12.7 & 428.7 \\
\hline & ODD & 106.2 & 140.9 & 965.6 & 75.7 & 93.5 & 11.6 & 394.4 \\
\hline & MOD & 99.0 & 152.7 & 3279.9 & 65.0 & 81.8 & 14.9 & 382.7 \\
\hline & OST & 115.3 & 150.3 & 990.1 & 76.6 & 103.8 & 12.0 & 404.7 \\
\hline & $A \backslash O P N$ & 102.1 & 133.4 & 844.5 & 76.7 & 92.3 & 11.2 & 393.2 \\
\hline & $S \backslash O P N$ & 142.7 & 180.0 & 1002.9 & 78.8 & 132.8 & 13.2 & 433.8 \\
\hline \multirow{8}{*}{$k=4$} & EDD & 59.6 & 138.4 & 1097.9 & 42.7 & 5.3 & 12.4 & 406.6 \\
\hline & MDD & 46.4 & 134.5 & 3364.1 & 34.3 & -14.6 & 12.6 & 386.7 \\
\hline & SLK & 37.4 & 102.6 & 676.7 & 36.3 & -18.3 & 10.9 & 383.0 \\
\hline & ODD & 62.9 & 143.6 & 921.2 & 43.3 & 9.1 & 12.4 & 410.3 \\
\hline & MOD & 51.0 & 138.0 & 2875.0 & 36.9 & -6.2 & 13.5 & 395.1 \\
\hline & OST & 78.3 & 152.9 & 1024.3 & 51.2 & 34.0 & 12.7 & 435.3 \\
\hline & $A \backslash O P N$ & 57.9 & 143.4 & 882.3 & 40.3 & 7.7 & 12.1 & 408.9 \\
\hline & $S \backslash O P N$ & 46.9 & 124.1 & 682.0 & 37.8 & -5.4 & 11.5 & 395.8 \\
\hline \multirow{7}{*}{$k=5$} & EDD & 18.2 & 111.4 & 569.1 & 16.2 & -112.1 & 11.5 & 389.4 \\
\hline & MDD & 15.1 & 106.7 & 748.9 & 14.2 & -122.1 & 11.6 & 379.5 \\
\hline & SLK & 26.8 & 156.0 & 1117.6 & 17.2 & -103.3 & 12.8 & 398.2 \\
\hline & ODD & 41.8 & 148.2 & 1330.9 & 28.2 & -70.5 & 13.6 & 431.1 \\
\hline & MOD & 29.1 & 149.7 & 1539.8 & 19.4 & -95.1 & 13.2 & 406.5 \\
\hline & OST & 35.6 & 124.7 & 761.7 & 28.2 & -73.0 & 12.7 & 428.6 \\
\hline & $A \backslash O P N$ & 39.5 & 167.9 & 1181.6 & 23.5 & -77.9 & 13.3 & 423.7 \\
\hline \multirow{9}{*}{$k=6$} & $S \backslash O P N$ & 31.9 & 155.5 & 1504.6 & 20.0 & -83.5 & 13.3 & 418.1 \\
\hline & EDD & 10.7 & 112.7 & 578.0 & 10.0 & -194.5 & 12.4 & 407.3 \\
\hline & MDD & 11.3 & 132.3 & 688.3 & 8.6 & -193.1 & 12.4 & 408.7 \\
\hline & SLK & 21.0 & 148.0 & 1088.5 & 14.2 & -168.9 & 14.2 & 433.0 \\
\hline & ODD & 16.9 & 155.3 & 1065.1 & 10.9 & -196.5 & 8.6 & 405.7 \\
\hline & MOD & 17.3 & 188.4 & 1069.2 & 10.0 & -189.0 & 13.5 & 412.9 \\
\hline & OST & 29.0 & 154.6 & 935.4 & 18.8 & -161.9 & 14.2 & $\mathbf{4 4 0 . 0}$ \\
\hline & $A \backslash O P N$ & 10.7 & 158.1 & 947.4 & 6.7 & -194.3 & 12.6 & 407.6 \\
\hline & $S \backslash O P N$ & 13.6 & 122.2 & 733.5 & 11.1 & -181.3 & 13.0 & 420.5 \\
\hline
\end{tabular}

The simulation experiments were also repeated using the due-date rules as the AGV rules. In this case, the same due-date scheduling rule was used as both machine and AGV rules. But no single rule improves mean tardiness noticeably (figure 4).

In the previous simulation studies (Sabuncuoglu and Hommertzheim 1990, 1992a), it is noted that the variance of the processing time is an important factor in the relative performance of the scheduling rules. Thus the experiments were repeated with higher variances for the processing times (i.e., coefficient of variation was increased from 30 to $40 \%$ ). 


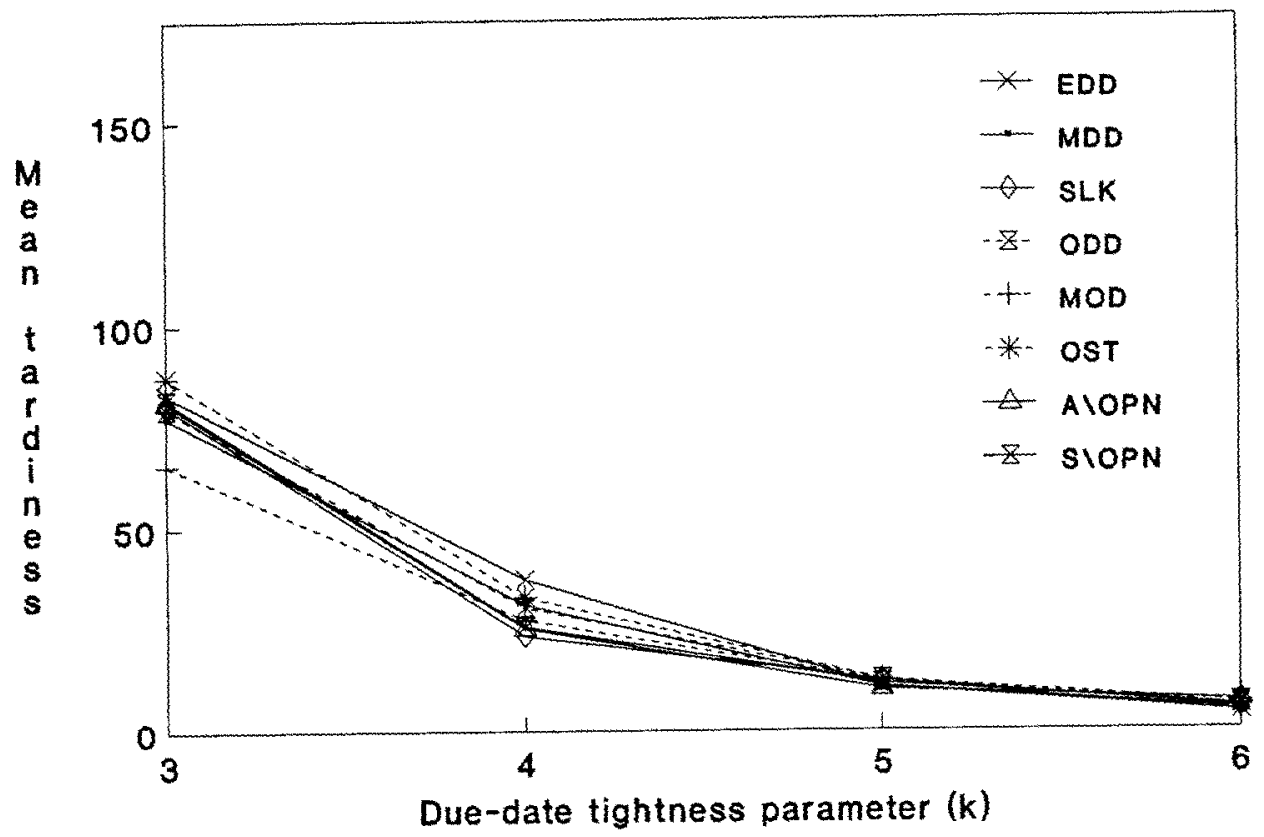

Figure 3. Normal with LQS rules.

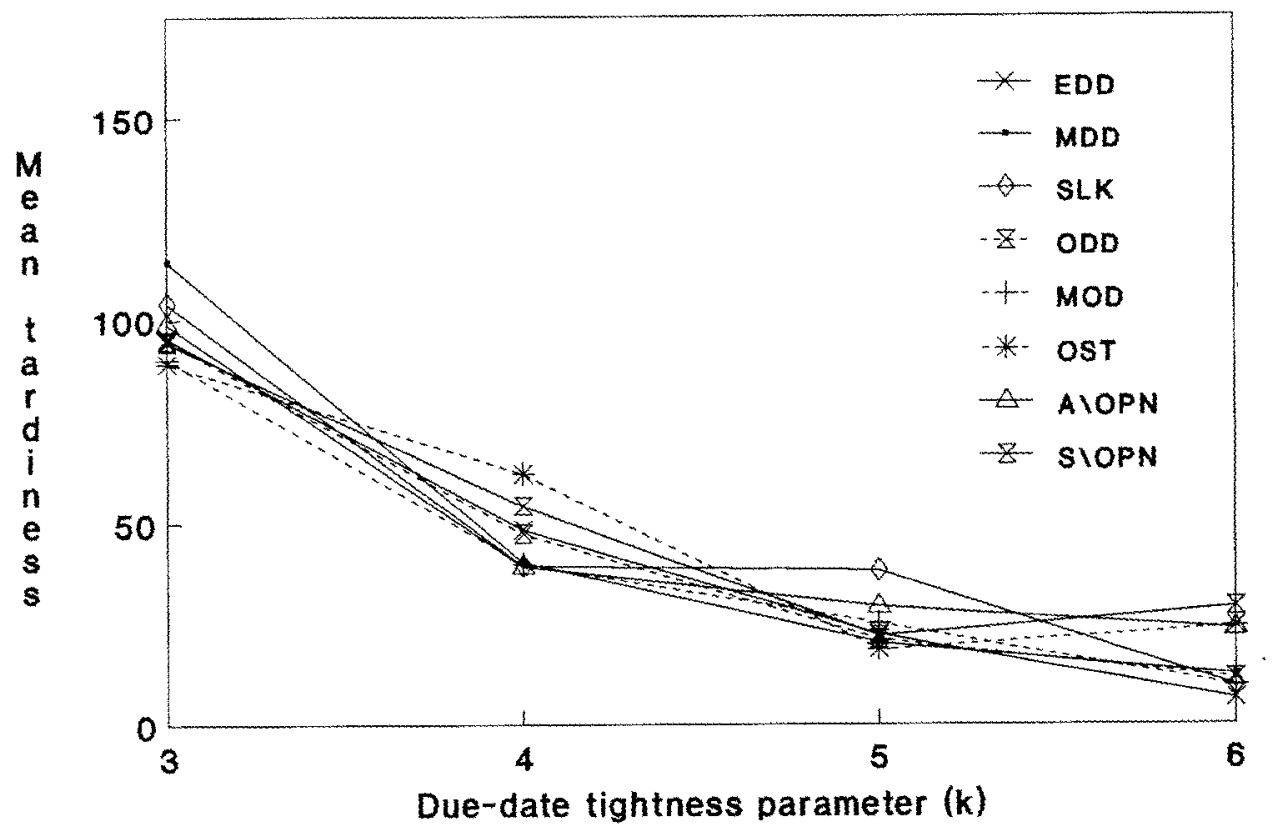

Figure 4. Normal with AGV due-date rules. 
As shown in figure 5, the performances of the rules are quite different at tight due-dates $(\mathrm{k}=3)$, as compared to the first case (figure 2). Specifically, MOD produces lower mean tardiness. However, the differences in their performances diminish as the due-dates are loosened. When the proportion of tardiness is considered, MOD yields consistently better performance than other rules (figure 6).

The above results and further pilot tests using different scheduling criteria indicate that the performance of scheduling rules change as the due-date tightness changes. No single rule dominates other rules. However, MOD has the tendency to improve due-date measures when due-dates are tight and the variance of operation time is high. This difficulty in distinguishing the relative effectiveness of the rules could be due to the variance of the normally distributed processing times. In this case, the due-date assignment procedure (TWK) and the due-date scheduling rules, which are based on the processing times with small variance, would not yield significantly different due-date performances.

\subsection{Analysis of the due-date scheduling rules using exponentially distributed processing times}

The exponential distribution is a commonly used processing-time distribution in the literature (Baker 1984; Baker and Kanet 1984). In general, the exponential distribution possesses very large variability. It is known from the earlier job-shop studies that the relative performances of the rules are more significant under high variability. Thus, the objective of this section is to repeat the simulation experiments using the exponential distribution and to observe the differences in performance of rules due to the increased variability. However, during the initial simulation runs, because of this increased variability, the system was saturated for most of the rules. Thus, the machine and AGV load levels were reduced. At the new condition, the mean operation time was reduced from 20.60 to 19.03 minutes, and the AGV speed was increased from 60 to 65 feet/minute, which results in average machine and AGV utilizations of 75 and $82 \%$, respectively.

The rest of the article is organized as follows. In the next subsection, due-date scheduling rules are compared with different AGV rules. In section 4.2.2, the scheduling rules are tested under exogenous due-date assignment. This is followed by comparison of rules at varying system load levels and queue capacities in sections 4.2 .3 and 4.2 .4 , respectively.

4.2.1. Due-date scheduling rules with different AGV rules. First, the FMS system was simulated using FCFS as the AGV scheduling rule. From the simulation results presented in table 5, it is obvious that MOD is a very effective rule for the mean-tardiness measure. It outperforms the other rules, especially when the due-dates are tight (i.e., $\mathbf{k}$ is small); ODD is next best. Furthermore, operation-based rules perform better than the part-based counterparts.

As depicted in figure 7 (see figure 3 for comparison with the normally distributed case), the differences in the relative performances of rules are more noticeable when due-dates are tight. Also, at tight due-dates $(\mathrm{k}=3$ and 4$)$, minimizing the mean flow-time results in better due-date performances. Thus, at small values of $\mathrm{k}$, the rule which yields minimum 


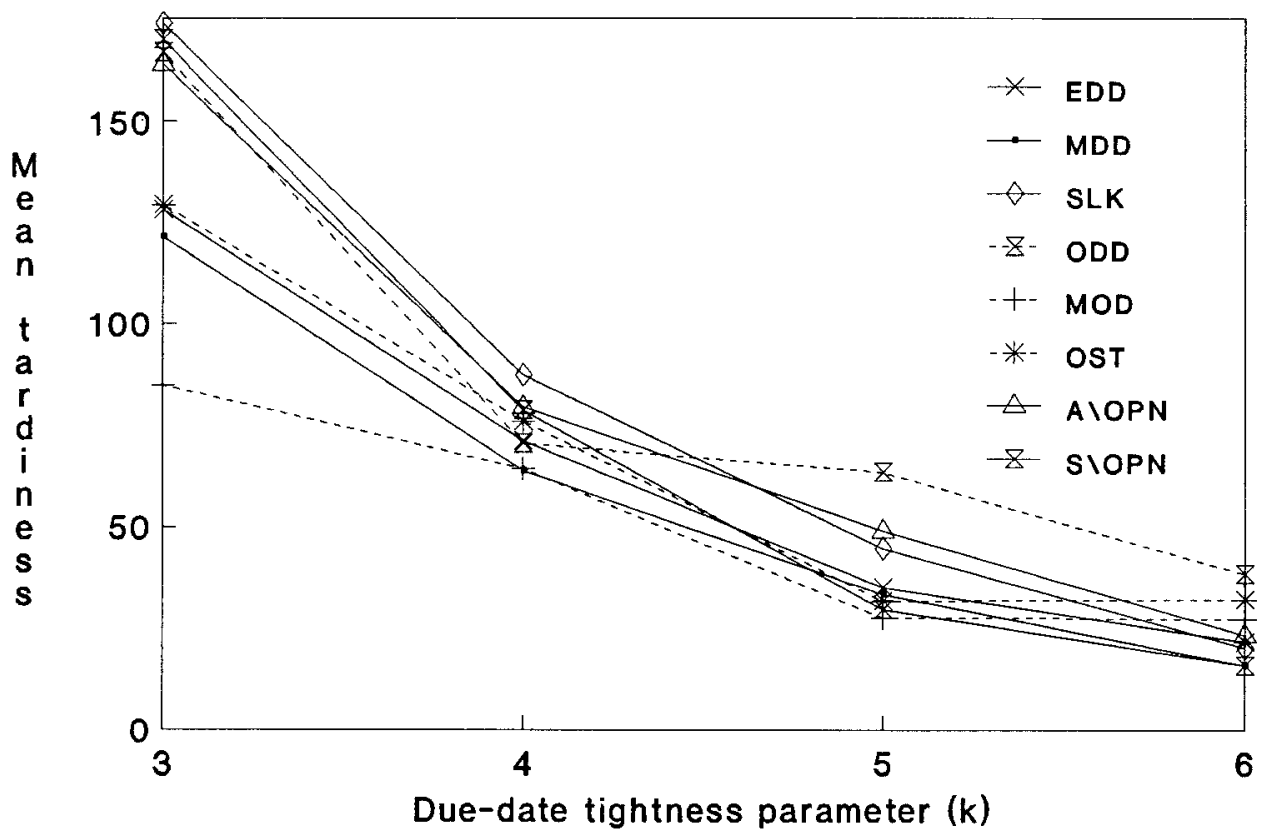

Figure 5. Normal with FCFS and 40 percent CV rules.

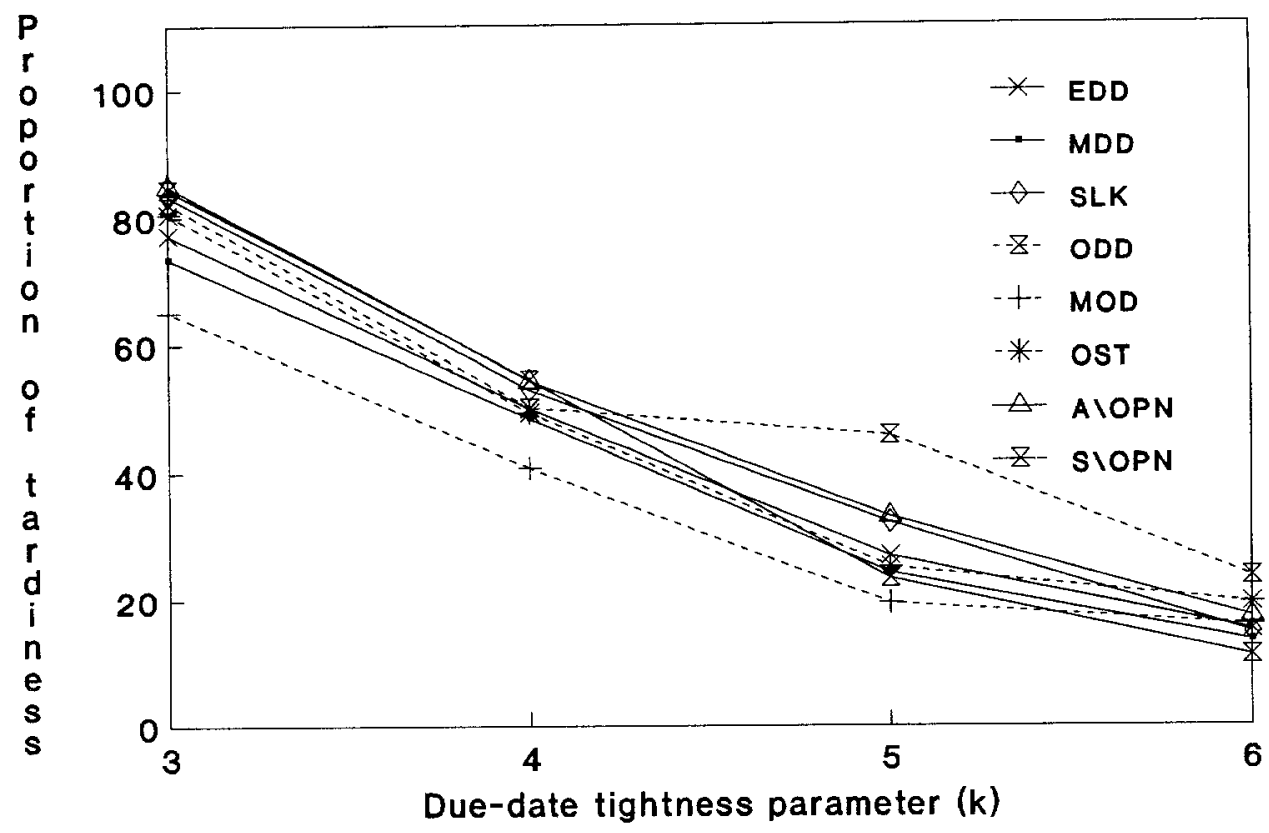

Figure 6. Normal with FCFS and 40 percent CV proportion. 
Table 5. Due-date performance of the scheduling rules at varying duc-date tightness, parameter (k) under exponentially distributed processing times (FCFS is the AGV rule).

\begin{tabular}{|c|c|c|c|c|c|c|c|c|}
\hline & \multirow[b]{2}{*}{ Due-Date Rules } & \multicolumn{7}{|c|}{ Due-Date Measures } \\
\hline & & MT & CMT & TMAX & $\mathbf{P T}(\%)$ & ML & VL & MF \\
\hline \multirow{8}{*}{$k=3$} & EDD & 202.2 & 244.6 & 1512.7 & 83.0 & 191.4 & 15.7 & 456.3 \\
\hline & MDD & 138.0 & 175.7 & 2305.3 & 78.5 & 126.2 & 14.4 & 391.1 \\
\hline & SLK & 195.5 & 225.5 & 1269.8 & 87.0 & 187.4 & 14.2 & 452.3 \\
\hline & ODD & 128.3 & 166.7 & 1047.4 & 77.0 & 112.4 & 13.0 & 377.3 \\
\hline & MOD & 70.7 & 108.6 & 1567.3 & 65.0 & 48.7 & 11.9 & 313.6 \\
\hline & OST & 160.8 & 200.1 & 1254.9 & 80.0 & 147.8 & 14.1 & 412.7 \\
\hline & $A \backslash O P N$ & 170.2 & 203.4 & 1355.9 & 84.0 & 159.9 & 13.9 & 424.8 \\
\hline & $S \backslash O P N$ & 207.5 & 236.3 & 1378.3 & 88.0 & 200.2 & 14.7 & 465.0 \\
\hline \multirow{8}{*}{$k=4$} & EDD & 108.7 & 175.0 & 1026.6 & 62.0 & 69.4 & 14.0 & 422.6 \\
\hline & MDD & 99.7 & 176.3 & 1512.7 & 56.3 & 58.1 & 14.5 & 411.3 \\
\hline & SLK & 124.5 & 192.2 & 1354.9 & 65.0 & 90.7 & 14.7 & 443.9 \\
\hline & ODD & 62.6 & 127.1 & 1011.9 & 50.0 & 7.6 & 12.7 & 360.9 \\
\hline & MOD & 37.3 & 97.2 & 853.9 & 38.2 & -30.1 & 12.1 & 323.1 \\
\hline & OST & 87.1 & 152.1 & 1028.7 & 57.3 & 40.0 & 13.3 & 393.2 \\
\hline & $\mathrm{A} \backslash \mathrm{OPN}$ & 91.3 & 160.1 & 1030.1 & 56.8 & 50.8 & 13.4 & 403.9 \\
\hline & $S \backslash \mathrm{OPN}$ & 100.5 & 168.0 & 1102.2 & 60.0 & 63.0 & 13.6 & 416.2 \\
\hline \multirow{8}{*}{$k=5$} & EDD & 65.0 & 156.1 & 1103.4 & 41.7 & -22.2 & 14.4 & 419.3 \\
\hline & MDD & 56.1 & 155.2 & 1242.2 & 36.1 & -36.5 & 14.4 & 405.0 \\
\hline & SLK & 78.0 & 174.2 & 1371.6 & 45.0 & -0.9 & 14.7 & 440.7 \\
\hline & ODD & 31.1 & 111.9 & 910.9 & 27.7 & -88.4 & 13.6 & 353.2 \\
\hline & MOD & 28.3 & 109.3 & 910.1 & 25.6 & -93.4 & 13.5 & 348.1 \\
\hline & OST & 37.0 & 117.2 & 809.2 & 31.6 & -75.2 & 13.6 & 366.3 \\
\hline & $A \backslash O P N$ & 48.5 & 107.5 & 873.8 & 44.9 & -43.4 & 13.6 & 397.7 \\
\hline & $S \backslash O P N$ & 65.2 & 150.5 & 1091.6 & 43.4 & -15.6 & 14.2 & 426.0 \\
\hline \multirow{8}{*}{$\mathrm{k}=6$} & EDD & 57.0 & 198.8 & 1550.5 & 29.0 & -84.3 & 16.0 & 445.5 \\
\hline & MDD & 41.7 & 163.6 & 1230.9 & 25.7 & -109.3 & 15.1 & 420.5 \\
\hline & SLK & 46.7 & 175.6 & 1171.8 & 26.8 & -100.6 & 15.3 & 429.3 \\
\hline & ODD & 18.7 & 120.6 & 904.6 & 15.8 & -174.9 & 14.5 & 354.9 \\
\hline & MOD & 18.4 & 110.3 & 811.0 & 16.0 & -171.6 & 14.5 & 358.2 \\
\hline & OST & 24.5 & 122.2 & 785.9 & 20.0 & -151.7 & 14.7 & 378.1 \\
\hline & $A \backslash O P N$ & 31.6 & 144.4 & 1034.3 & 21.9 & -124.8 & 14.5 & 405.0 \\
\hline & $S \backslash O P N$ & 47.6 & 184.4 & 1326.9 & 26.0 & -98.4 & 15.5 & 431.4 \\
\hline
\end{tabular}

flow-time also produces minimum mean tardiness, mean-conditional tardiness, and proportion of tardiness. However, as $\mathrm{k}$ increases, the differences in performances of rules become smaller.

As can also be noted, the MOD rule, which is very effective in reducing the mean tardiness, also yields a better mean lateness at the tighter due-dates. However, as the due-date tightness decreases, rules such a OST, which yields poorer mean-tardiness performance than MOD, result in lower mean lateness. This occurs because for loose due-dates, poor 


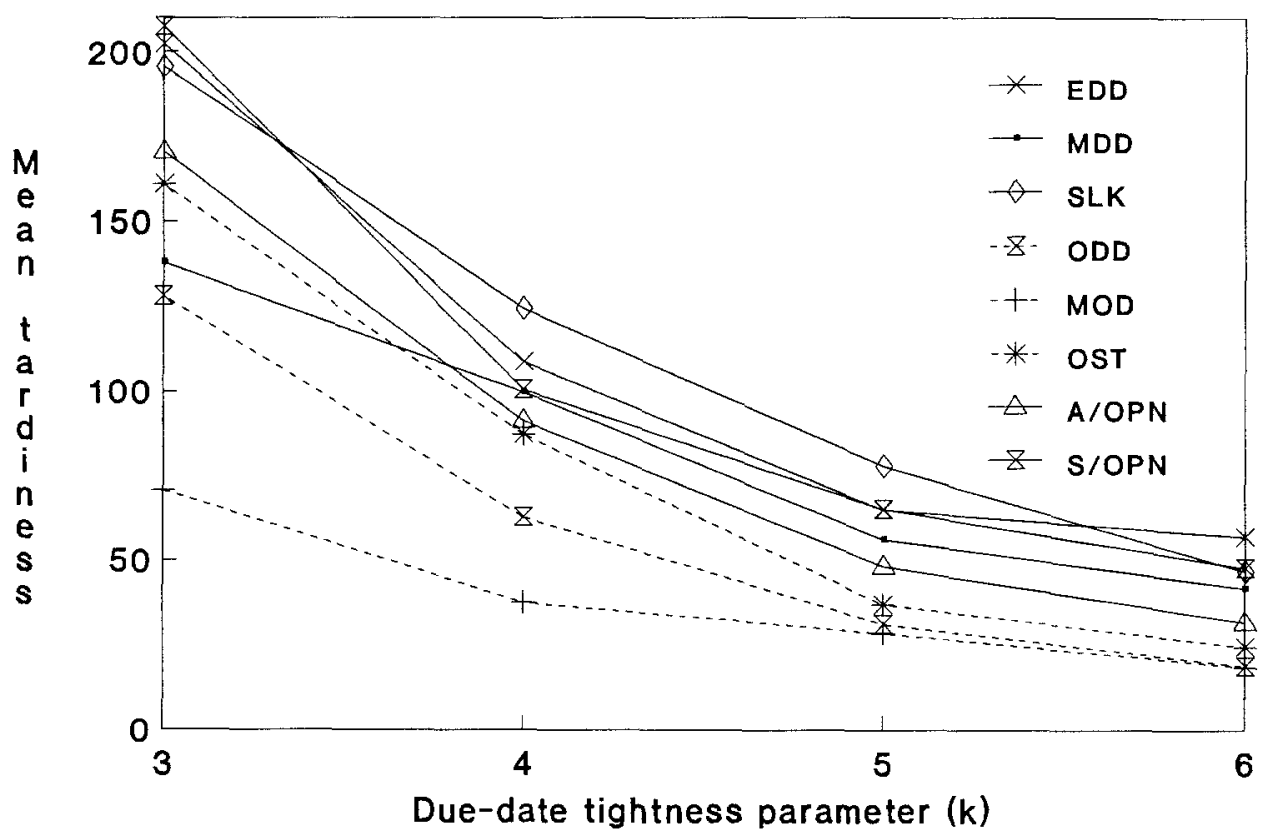

Figure 7. Mean tardiness performances of operaton and job-based due-date.

mean-tardiness performance results in a fewer early part completions, at a cost of some tardy parts. Since the marginal gain due to reducing early part completions is greater than the gain obtained by reducing mean tardiness, mean lateness is improved.

Similar observations are made when using LQS as when employing the AGV rule (figure 8). However, due-date performances of the machine scheduling rules with LQS are better than with FCFS (recall that the same type of improvement was also observed with LQS for the normally distributed case). In general, the MOD rule performs better than other rules; ODD is next best. Other rules could not compete successfully with the above rules. Again, operation-based rules are better than the part-based rules.

Similar behavior is also observed when using the same due-date scheduling rule for both the machine and AGV rule (figure 9). MOD and ODD still yield better mean-tardiness performances. Mean-tardiness performances of due-date rules as AGV rules are also better than the same rules with the FCFS/AGV rule combination. When they are compared to LQS rule combinations, LQS appears to perform better. However, this improvement in tardiness by LQS is not the same for each of the machine scheduling rules. For example, while slack-based rules, which were found to be the best rules in previous FMS studies (Montazeri and Wassenhowe 1989; Choi and Malstrom 1988), improve the mean tardiness with LQS, the same amount of improvement is not observed for MOD rules (figure 10). This interaction effect indicates that marginal improvement by AGV rule is smallest when used with a better machine scheduling rule. 


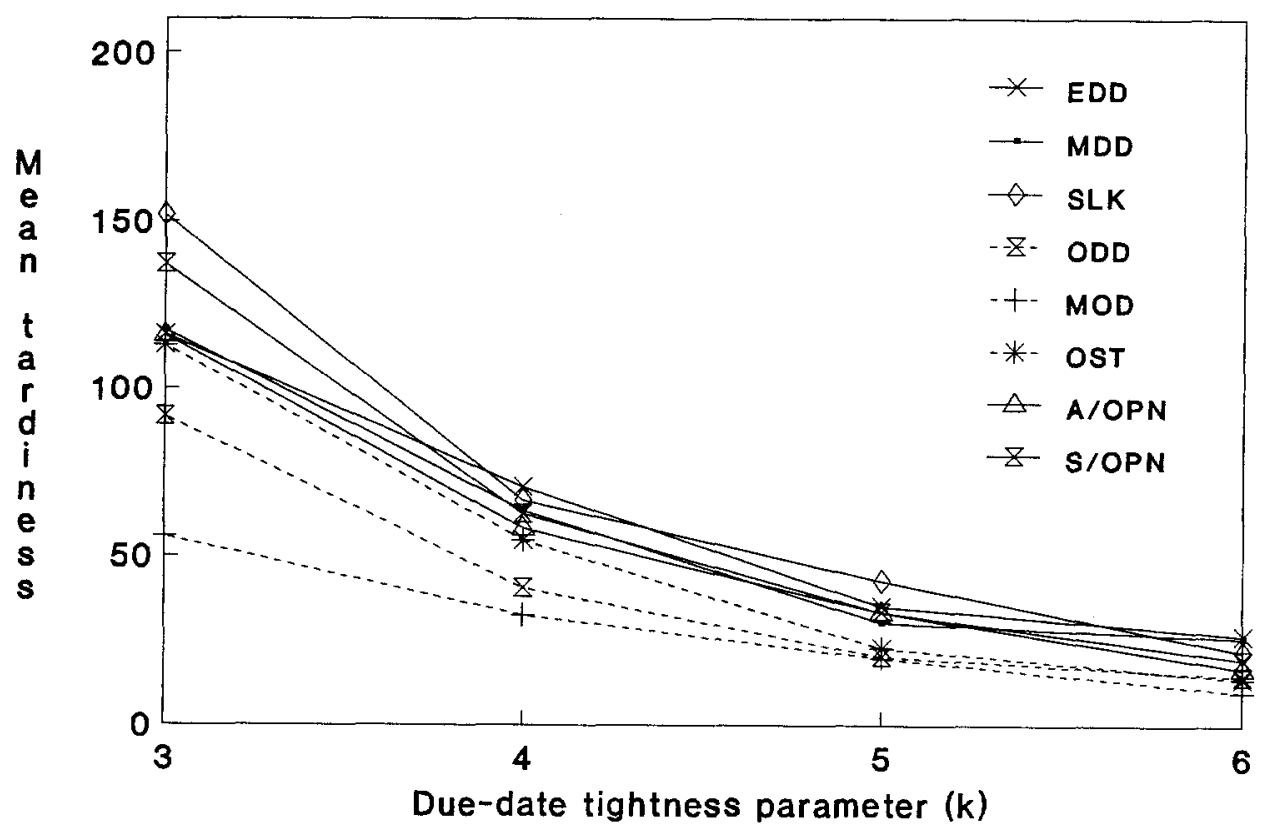

Figure 8. Mean tardiness performances of operation and job-based due-date.

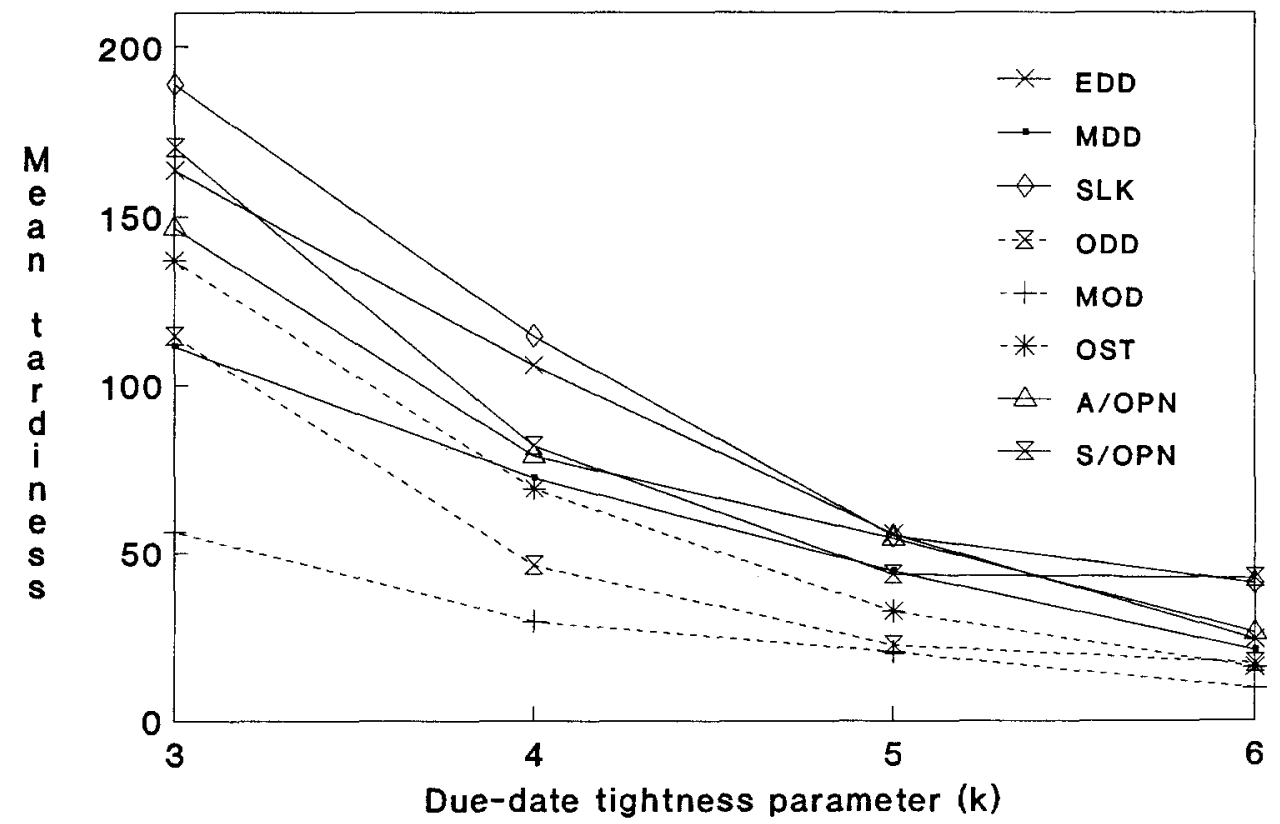

Figure 9. Mean tardiness due date as AGV rules at varying. 


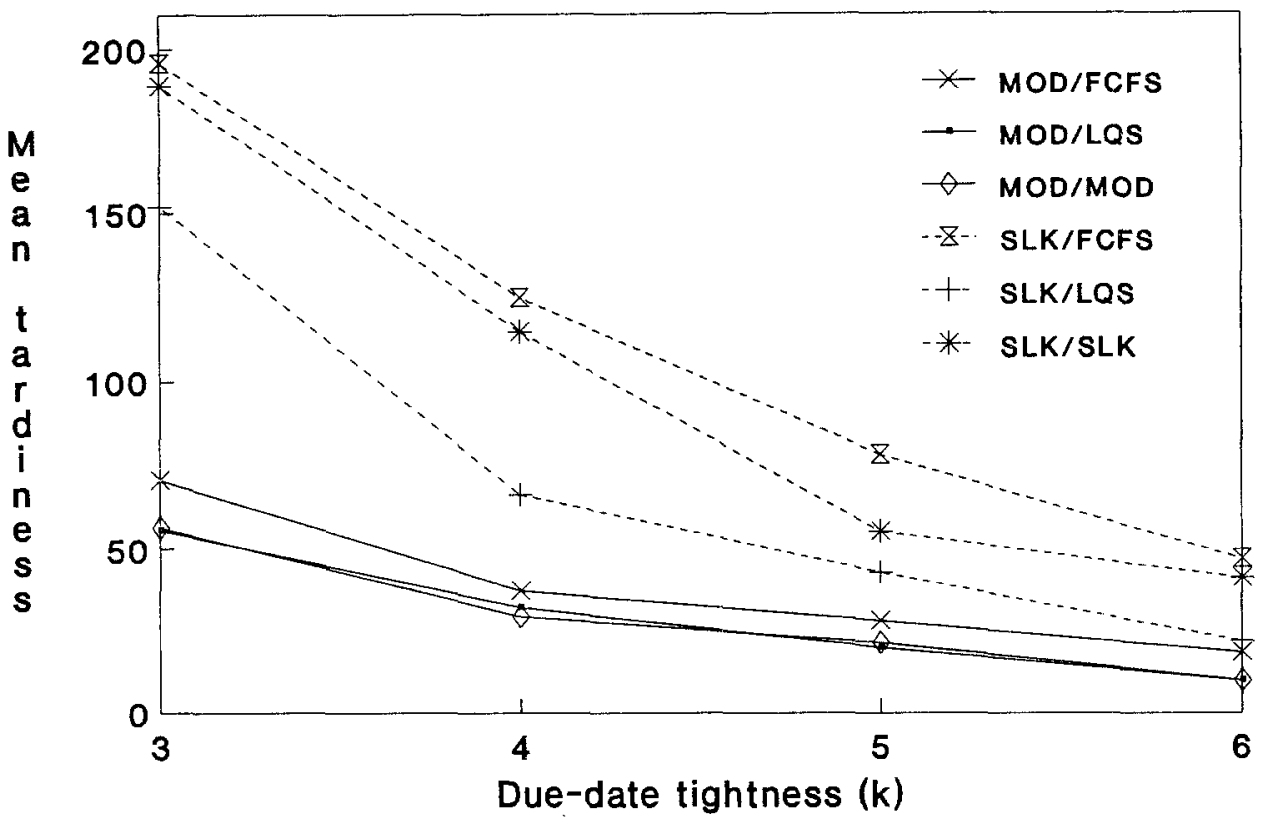

Figure 10. Mean tardiness due date as AG rules.

4.2.2. Exogenous due-date assignment. Up to this point, it was assumed that due-dates were set by the company, based on expected flow allowances (i.e., endogenous due-date assignment). However, customers can also determine the due-dates which are usually random in nature. In order to represent this situation, the original due-date assignment method TWK was replaced with a random assignment procedure. According to this procedure, the flow allowance was determined by using the uniform distribution and then added to the total processing times to set the due-dates.

Four different cases were considered. In the first case, the parameters of the uniform distribution were set to 0 and 400 , with a range $(R)$ of 400 . Later the ranges were increased to 500,600 , and 700 . Recall that in these experiments, only the upper limit of the uniform distribution was increased while the lower limit was maintained at zero. Thus, as the range increased, the mean and the variance of the uniformly distributed flow allowances increased. The performances of the due-date scheduling rules under this new due-date assignment procedure are shown in figure 11 and table 6. In general, MOD performs better than other rules. It not only minimizes the mean flow-time considerably but also achieves better duedate performance. The relative performances of other rules vary as the range of uniformly distributed due-dates changes.

4.2.3. Sensitivity of the results to varying machine and AGV load levels. The scheduling rules were also compared at varying machine and AGV load (utilization) levels. Four machine and two AGV load levels were considered (table 7). As before, the rules were compared at varying levels of the tightness parameter $(\mathrm{k})$. 


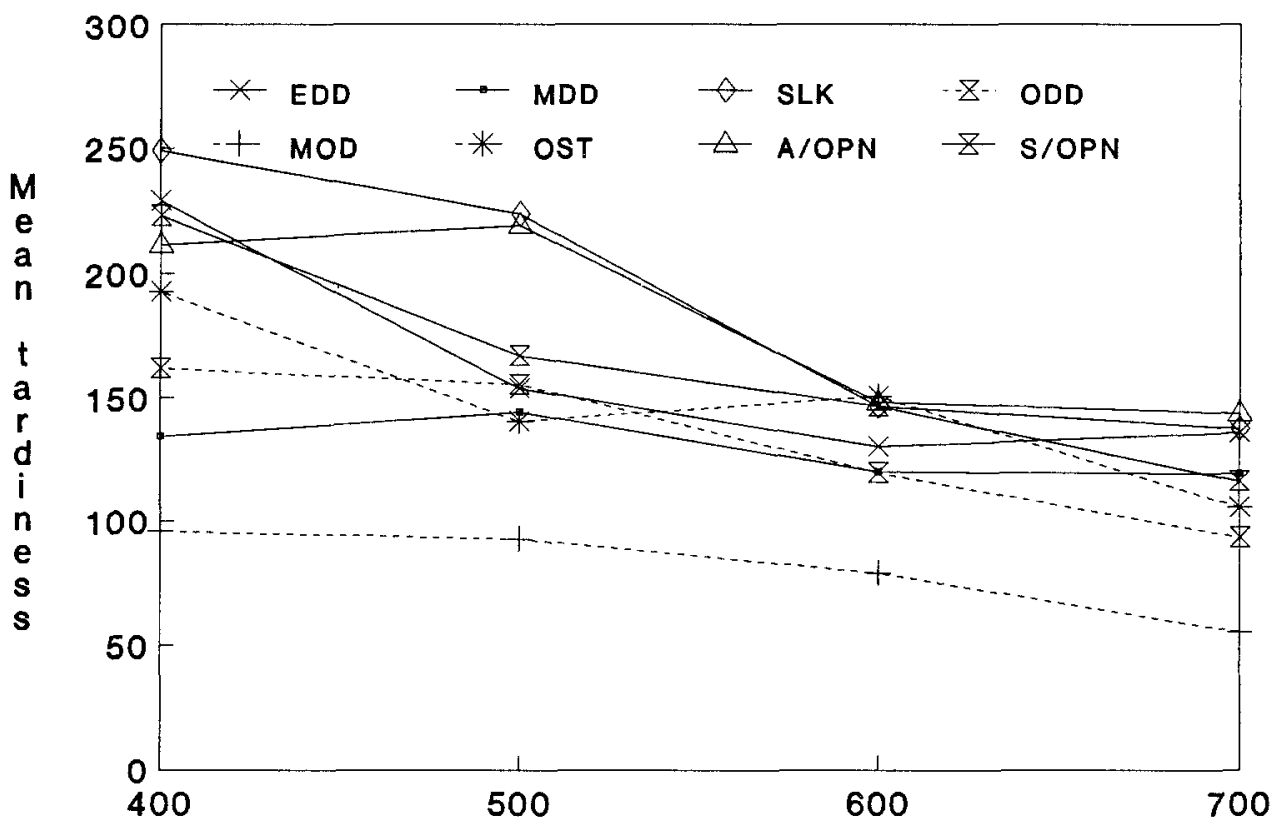

Ranges of uniformly distributed due-dates

Figure 11. Mean tardiness performances exogenous.

The simulation results are displayed in tables 8 and 9 and figure 12. In general, better mean tardiness performances are obtained for each rule when the load level is reduced and/or the due-date tightness parameter is decreased. Also, differences in relative performances of the rules diminish as the load levels and the flow allowance are reduced. Moreover, the rules perform better with the AGV scheduling rule LQS than with FCFS. Operationbased, due-date scheduling rules, MOD, ODD, and OST, result in better performances than part-based versions of MDD, EDD, and SLK. In mot of the cases, MOD is the preferable rule, followed by ODD and OST. MDD is still a better rule than EDD. EDD and SLK display better results than A/OPN and S/OPN.

4.2.4. Sensitivity of the results to varying queue sizes. The effects of different queue capacities on the relative performance of due-date scheduling rules were also investigated in this study. Eight scheduling rules were compared at 3 different queue capacities under varying due-date tightnesses.

As shown in table 10, MOD is still the preferable rule. In particular, its performance is the best for the tighter due-dates when the queue capacity is small. In general, MDD performs better than EDD and SLK. It also yields better performance than ODD when due-dates tightness and queue capacity is increased and due-dates are loosened. Again, operation-based rules result in better mean tardiness than their part-based counterparts. 
Table 6. Due-date performance of scheduling rules when the due-dates are set by the random due-date assignment

\begin{tabular}{|c|c|c|c|c|c|c|c|c|}
\hline & \multirow[b]{2}{*}{ Due-Date Rules } & \multicolumn{7}{|c|}{ Due-Date Measures } \\
\hline & & $\mathrm{MT}$ & CMT & TMAX & PT $(\%)$ & ML & VL & MF \\
\hline \multirow{8}{*}{$R=400$} & EDD & 229.0 & 281.3 & 1241.5 & 81.1 & 210.0 & 15.7 & 497.5 \\
\hline & MDD & 134.5 & 192.2 & 2708.9 & 70.0 & 108.8 & 14.9 & 396.1 \\
\hline & SLK & 284.8 & 292.7 & 1528.9 & 84.9 & 233.3 & 16.1 & 521.9 \\
\hline & ODD & 162.0 & 228.0 & 1325.9 & 71.0 & 131.2 & 15.2 & 420.7 \\
\hline & MOD & 95.8 & 158.1 & 1326.6 & 60.1 & 54.4 & 13.7 & 342.6 \\
\hline & OST & 193.0 & 254.5 & 1470.3 & 75.9 & 166.6 & 15.7 & 456.0 \\
\hline & $\mathrm{A} / \mathrm{OPN}$ & 211.7 & 262.7 & 1428.1 & 80.5 & 191.3 & 15.7 & 479.9 \\
\hline & S/OPN & 223.4 & 269.2 & 1207.4 & 82.9 & 207.4 & 16.0 & 494.5 \\
\hline \multirow{8}{*}{$R=500$} & EDD & 153.9 & 222.7 & 1438.3 & 69.1 & 111.8 & 15.1 & 453.3 \\
\hline & MDD & 144.3 & 220.9 & 2273.5 & 65.3 & 103.9 & 16.1 & 443.2 \\
\hline & SLK & 223.9 & 291.2 & 1945.6 & 76.9 & 196.3 & 17.1 & 534.1 \\
\hline & ODD & 155.7 & 236.1 & 1257.4 & 60.5 & 108.2 & 15.6 & 446.0 \\
\hline & MOD & 92.6 & 170.8 & 1820.3 & 54.1 & 27.9 & 14.7 & 366.8 \\
\hline & OST & 140.5 & 212.2 & 1289.7 & 66.1 & 94.1 & 15.2 & 431.2 \\
\hline & A/OPN & 219.5 & 286.6 & 1900.5 & 76.5 & 190.8 & 17.1 & 528.5 \\
\hline & S/OPN & 167.1 & 221.7 & 1204.6 & 75.5 & 136.9 & 14.9 & 475.5 \\
\hline \multirow{8}{*}{$R=600$} & EDD & 130.2 & 209.7 & 1407.7 & 62.2 & 72.8 & 15.3 & 459.1 \\
\hline & MDD & 120.2 & 213.6 & 1913.4 & 56.3 & 56.3 & 16.2 & 445.4 \\
\hline & SLK & 146.6 & 228.8 & 1485.9 & 64.1 & 92.7 & 15.9 & 480.8 \\
\hline & ODD & 119.8 & 211.4 & 1337.9 & 56.3 & 45.9 & 15.9 & 435.0 \\
\hline & MOD & 79.1 & 171.7 & 1297.1 & 46.0 & -12.8 & 15.2 & 376.7 \\
\hline & OST & 150.8 & 246.7 & 1391.5 & 61.3 & 84.5 & 16.7 & 473.2 \\
\hline & $\mathrm{A} / \mathrm{OPN}$ & 148.6 & 228.4 & 1644.3 & 64.9 & 98.7 & 16.2 & 448.6 \\
\hline & S/OPN & 146.8 & 220.1 & 1398.8 & 66.4 & 96.1 & 16.1 & 485.7 \\
\hline \multirow{8}{*}{$\mathrm{R}=700$} & EDD & 146.0 & 253.4 & 1581.4 & 57.7 & 69.6 & 17.1 & 508.3 \\
\hline & MDD & 119.4 & 228.3 & 1609.5 & 52.2 & 38.4 & 17.0 & 447.2 \\
\hline & SLK & 137.9 & 233.1 & 1403.3 & 58.8 & 64.2 & 16.5 & 504.7 \\
\hline & ODD & 93.3 & 198.0 & 1094.0 & 47.0 & -15.9 & 16.2 & 422.4 \\
\hline & MOD & 55.2 & 147.1 & 1442.4 & 37.4 & -71.0 & 10.6 & 364.6 \\
\hline & OST & 105.7 & 206.7 & 1391.3 & 51.0 & 5.1 & 16.5 & 446.7 \\
\hline & $\mathrm{A} / \mathrm{OPN}$ & 144.1 & 241.2 & 1566.4 & 59.7 & 77.9 & 16.7 & 513.4 \\
\hline & S/OPN & 116.2 & 208.0 & 1270.2 & 56.0 & 41.8 & 15.9 & 480.2 \\
\hline
\end{tabular}

Table 7. Experimental conditions for testing scheduling rules under varying load levels (utilization levels).

\begin{tabular}{lccccc}
\hline & & \multicolumn{4}{c}{ Machine Load Levels (\%) } \\
\cline { 4 - 5 } Input Parameter & $\begin{array}{c}\text { AGV Load } \\
\text { Levels (\%) }\end{array}$ & 77.5 & 75 & 70 & 65 \\
\hline Mean operation & 70.0 & 19.03 & 19.03 & 19.03 & 19.03 \\
time (min) & 82.5 & 19.03 & 19.03 & 19.03 & 19.03 \\
Interarrival time & 70.0 & 14.50 & 15.00 & 16.00 & 17.00 \\
(min) & 82.5 & 14.50 & 15.00 & 16.00 & 17.00 \\
AGV speed & 70.0 & 82.50 & 78.00 & 71.00 & 65.50 \\
(ft/min) & 82.5 & 68.50 & 65.00 & 59.30 & 55.00 \\
\hline
\end{tabular}


Table 8. Mean-tardiness performance of due-date scheduling rules with FCFS and LQS AGV rules (AGV utilization at $82.5 \%$ ).

\begin{tabular}{|c|c|c|c|c|c|c|c|c|c|}
\hline \multirow[b]{3}{*}{ Rules } & \multirow[b]{3}{*}{$\mathrm{k}$} & \multicolumn{8}{|c|}{ Machine Load Levels (\%) } \\
\hline & & \multicolumn{2}{|c|}{77.5} & \multicolumn{2}{|c|}{75} & \multicolumn{2}{|c|}{70} & \multicolumn{2}{|c|}{65} \\
\hline & & FCFS & LQS & FCFS & LQS & FCFS & LQS & FCFS & LQS \\
\hline & 3 & 298.1 & 172.6 & 202.2 & 116.3 & 107.9 & 84.2 & 76.1 & 61.7 \\
\hline & 4 & 249.4 & 103.7 & 108.7 & 70.3 & 65.2 & 43.0 & 38.1 & 28.6 \\
\hline \multirow[t]{4}{*}{ EDD } & 5 & 167.5 & 55.9 & 65.0 & 35.1 & 26.9 & 20.3 & 16.0 & 14.7 \\
\hline & 6 & 82.1 & 34.0 & 57.0 & 26.6 & 14.1 & 12.5 & 9.3 & 8.0 \\
\hline & 3 & 191.0 & 130.3 & 138.0 & 117.7 & 85.5 & 53.2 & 64.6 & 51.5 \\
\hline & 4 & 126.3 & 87.5 & 99.7 & 63.1 & 42.7 & 35.0 & 30.0 & 25.8 \\
\hline \multirow[t]{4}{*}{ MDD } & 5 & 103.4 & 49.3 & 56.1 & 30.3 & 28.5 & 17.4 & 15.6 & 13.8 \\
\hline & 6 & 61.9 & 36.7 & 41.7 & 25.9 & 16.7 & 12.0 & 9.3 & 8.0 \\
\hline & 3 & 285.8 & 182.6 & 195.5 & 152.1 & 121.6 & 92.1 & 78.2 & 66.5 \\
\hline & 4 & 190.7 & 114.6 & 124.5 & 66.3 & 59.8 & 41.9 & 36.0 & 31.7 \\
\hline \multirow[t]{4}{*}{ SLK } & 5 & 96.7 & 62.4 & 56.1 & 42.7 & 32.8 & 21.9 & 17.8 & 17.6 \\
\hline & 6 & 46.7 & 37.2 & 41.7 & 21.9 & 17.7 & 13.3 & 9.5 & 8.0 \\
\hline & 3 & 188.4 & 114.6 & 128.3 & 91.4 & 76.1 & 61.5 & 49.8 & 42.7 \\
\hline & 4 & 85.5 & 53.3 & 62.6 & 40.3 & 29.9 & 27.5 & 22.5 & 19.6 \\
\hline \multirow[t]{4}{*}{ ODD } & 5 & 60.5 & 31.8 & 31.1 & 20.3 & 17.2 & 11.3 & 9.4 & 8.4 \\
\hline & 6 & 43.6 & 21.8 & 18.2 & 14.6 & 9.8 & 6.8 & 5.9 & 4.4 \\
\hline & 3 & 90.9 & 66.2 & 70.7 & 55.6 & 45.5 & 40.0 & 40.2 & 30.0 \\
\hline & 4 & 54.5 & 41.0 & 37.3 & 32.3 & 23.1 & 19.5 & 18.1 & 13.2 \\
\hline \multirow[t]{4}{*}{ MOD } & 5 & 41.9 & 29.9 & 28.3 & 19.8 & 12.5 & 11.8 & 9.1 & 7.4 \\
\hline & 6 & 39.2 & 15.9 & 18.4 & 9.9 & 9.7 & 7.0 & 5.7 & 4.7 \\
\hline & 3 & 261.5 & 134.5 & 160.8 & 112.9 & 83.5 & 78.3 & 65.6 & 54.2 \\
\hline & 4 & 116.7 & 77.7 & 87.1 & 54.5 & 35.3 & 29.7 & 30.2 & 21.4 \\
\hline \multirow[t]{4}{*}{ OST } & 5 & 66.7 & 37.2 & 37.0 & 22.8 & 19.0 & 12.6 & 11.2 & 8.0 \\
\hline & 6 & 38.2 & 21.3 & 24.6 & 14.0 & 9.9 & 8.6 & 6.6 & 4.9 \\
\hline & 3 & 288.0 & 170.5 & 170.2 & 115.9 & 112.3 & 84.8 & 62.6 & 55.9 \\
\hline & 4 & 182.3 & 90.9 & 91.3 & 58.0 & 49.3 & 39.2 & 32.2 & 22.3 \\
\hline \multirow[t]{4}{*}{$\mathrm{A} / \mathrm{OPN}$} & 5 & 167.7 & 49.5 & 48.4 & 33.5 & 22.4 & 15.5 & 12.3 & 10.8 \\
\hline & 6 & 51.8 & 32.5 & 31.7 & 16.9 & 14.2 & 10.6 & 8.6 & 7.0 \\
\hline & 3 & 312.6 & 163.2 & 207.5 & 137.3 & 101.0 & 92.9 & 91.0 & 64.3 \\
\hline & 4 & 295.7 & 102.1 & 105.5 & 62.2 & 47.9 & 43.7 & 31.0 & 29.7 \\
\hline \multirow[t]{3}{*}{ S/OPN } & 5 & 169.5 & 52.9 & 65.2 & 33.5 & 27.3 & 18.3 & 16.5 & 13.3 \\
\hline & 6 & 101.3 & 35.6 & 47.6 & 19.6 & 14.2 & 10.2 & 8.8 & 7.0 \\
\hline & 7 & 55.5 & 22.4 & 29.0 & 13.8 & 11.1 & 7.6 & 5.4 & 4.6 \\
\hline
\end{tabular}


Table 9. Mean-tardiness performance of machine scheduling rules with FCFS and LQS AGV rules (AGV utilization at $70 \%$ ).

\begin{tabular}{|c|c|c|c|c|c|c|c|c|c|}
\hline \multirow[b]{3}{*}{ Rules } & \multirow[b]{3}{*}{ k } & \multicolumn{8}{|c|}{ Machine Load Levels (\%) } \\
\hline & & \multicolumn{2}{|c|}{77.5} & \multicolumn{2}{|c|}{75} & \multicolumn{2}{|c|}{70} & \multicolumn{2}{|c|}{65} \\
\hline & & FCFS & LQS & FCFS & LQS & FCFS & LQS & FCFS & LQS \\
\hline & 3 & 251.3 & 142.3 & 144.8 & 108.7 & 81.4 & 66.3 & 50.5 & 47.2 \\
\hline & 4 & 145.8 & 85.5 & 82.7 & 59.5 & 43.8 & 32.3 & 21.8 & 19.3 \\
\hline \multirow[t]{4}{*}{ EDD } & 5 & 90.7 & 43.2 & 45.8 & 31.4 & 17.3 & 14.5 & 11.4 & 5.1 \\
\hline & 6 & 57.3 & 23.0 & 30.7 & 15.1 & 7.9 & 8.6 & 4.3 & 4.4 \\
\hline & 3 & 151.2 & 120.3 & 116.1 & 89.0 & 63.6 & 62.2 & 42.3 & 38.4 \\
\hline & 4 & 112.9 & 68.7 & 58.9 & 48.7 & 41.8 & 28.5 & 22.0 & 17.3 \\
\hline \multirow[t]{4}{*}{ MDD } & 5 & 63.7 & 43.6 & 40.3 & 30.9 & 14.7 & 11.0 & 10.0 & 5.4 \\
\hline & 6 & 38.0 & 25.4 & 24.2 & 15.8 & 8.3 & 7.8 & 4.5 & 4.3 \\
\hline & 3 & 237.0 & 159.2 & 147.6 & 125.2 & 84.4 & 73.5 & 58.0 & 54.3 \\
\hline & 4 & 168.5 & 95.7 & 92.0 & 63.7 & 39.0 & 33.9 & 22.8 & 23.7 \\
\hline \multirow[t]{4}{*}{ SLK } & 5 & 70.0 & 54.6 & 40.7 & 32.9 & 16.3 & 17.9 & 10.5 & 5.1 \\
\hline & 6 & 44.4 & 28.3 & 21.1 & 16.2 & 7.9 & 9.2 & 6.1 & 5.7 \\
\hline & 3 & 159.3 & 115.4 & 106.8 & 82.6 & 56.6 & 46.5 & 32.9 & 29.7 \\
\hline & 4 & 65.0 & 51.6 & 44.7 & 34.6 & 19.6 & 18.3 & 10.3 & 10.7 \\
\hline \multirow[t]{4}{*}{ ODD } & 5 & 39.8 & 21.5 & 19.8 & 14.9 & 8.8 & 7.1 & 4.4 & 3.5 \\
\hline & 6 & 26.8 & 14.7 & 13.8 & 11.4 & 4.9 & 4.5 & 2.6 & 2.7 \\
\hline & 3 & 90.9 & 51.7 & 45.8 & 42.7 & 31.7 & 29.8 & 22.1 & 21.8 \\
\hline & 4 & 42.6 & 37.8 & 27.3 & 26.5 & 16.0 & 13.5 & 8.8 & 8.3 \\
\hline \multirow[t]{8}{*}{ MOD } & 5 & 29.7 & 20.4 & 17.1 & 13.5 & 6.8 & 6.7 & 4.7 & 3.7 \\
\hline & 6 & 18.7 & 13.6 & 10.9 & 8.7 & 4.1 & 4.3 & 2.6 & 2.4 \\
\hline & 3 & 186.4 & 128.6 & 145.5 & 91.6 & 69.5 & 60.5 & 45.8 & 41.8 \\
\hline & 4 & 92.0 & 64.0 & 46.8 & 39.7 & 25.6 & 18.8 & 14.6 & 12.9 \\
\hline & 5 & 48.2 & 23.6 & 21.6 & 19.3 & 7.9 & 9.5 & 5.5 & 4.9 \\
\hline & 6 & 28.9 & 17.1 & 11.9 & 10.1 & 7.2 & 5.7 & 4.0 & 3.3 \\
\hline & 3 & 181.4 & 128.4 & 134.3 & 106.1 & 74.8 & 62.0 & 44.7 & 40.0 \\
\hline & 4 & 141.3 & 78.2 & 71.9 & 49.8 & 27.0 & 26.3 & 15.5 & 14.0 \\
\hline \multirow[t]{4}{*}{ A/OPN } & 5 & 72.5 & 39.5 & 52.1 & 19.2 & 13.8 & 13.1 & 6.7 & 6.8 \\
\hline & 6 & 30.0 & 20.5 & 20.8 & 13.5 & 7.5 & 6.6 & 4.4 & 3.3 \\
\hline & 3 & 204.1 & 155.5 & 146.9 & 116.5 & 85.1 & 72.5 & 52.6 & 48.8 \\
\hline & 4 & 201.1 & 89.1 & 70.5 & 57.4 & 36.8 & 26.7 & 19.0 & 17.4 \\
\hline \multirow[t]{2}{*}{ S/OPN } & 5 & 84.9 & 38.4 & 41.3 & 24.0 & 14.1 & 12.7 & 9.1 & 8.0 \\
\hline & 6 & 74.0 & 22.3 & 22.1 & 16.7 & 7.6 & 6.9 & 5.3 & 4.7 \\
\hline
\end{tabular}




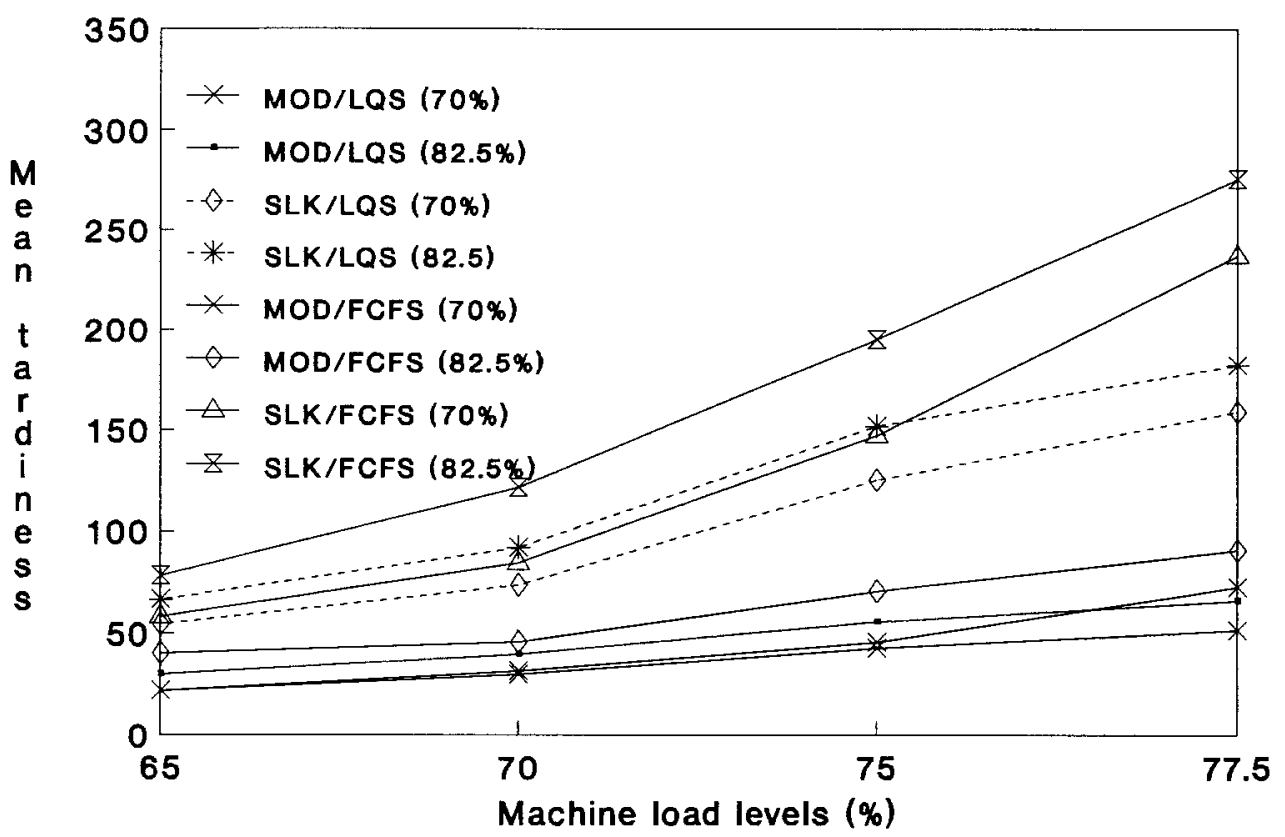

Figure 12. Rules at varying load levels.

\section{Conclusions and directions for future research}

In this article, due-date performances of machine and AGV scheduling rules were studied with an FMS simulation model. The results indicate that no single machine scheduling rule yields superior due-date performance for normally distributed processing times. When the variance of normal distribution increases, the relative performance of the rules becomes more visible. However, only MOD appears to perform well at tight due-dates. As an AGV rule, LQS produces better due-date performances.

In contrast to normally distributed processing times, accentuated differences for performances of the due-date scheduling rules are observed in the exponential case. MOD, which uses operation due-dates as milestones and has some characteristics of SPT, perform very well. Its performance is the best when the tightness parameter is small. Under exogenous due-date assignment, MOD still produces the better results. It only requires setting milestones to the operations of a part, which can be easily determined in a computer-aided manufacturing environment.

Among the AGV rules, LQS is the preferable rule, even though it does not use due-date information. This may be due to the effectiveness of LQS in reducing the mean flow-time.

In most cases, operation-based rules perform better than part-based rules. Finally, the relative performances of the rules become more noticeable when the machine and AGV loads increase, and queue capacities decrease. 
Table 10. Mean tardiness performance of scheduling rules at varying queue capacities (FCFS used as the AGV rule).

\begin{tabular}{|c|c|c|c|c|}
\hline \multirow[b]{2}{*}{ Due-Date Tightness } & \multirow[b]{2}{*}{ Due-Date Rules } & \multicolumn{3}{|c|}{ Queue Capacities } \\
\hline & & $Q=4$ & $Q=5$ & $Q=6$ \\
\hline \multirow{8}{*}{$\mathrm{k}=3$} & EDD & 309.67 & 202.20 & 146.33 \\
\hline & MDD & 226.03 & 138.01 & 103.67 \\
\hline & SLK & 389.01 & 195.47 & 147.72 \\
\hline & ODD & 230.92 & 128.29 & 102.35 \\
\hline & MOD & 110.41 & 70.69 & 48.51 \\
\hline & OST & 313.79 & 160.77 & 117.06 \\
\hline & $\mathrm{A} / \mathrm{OPN}$ & 299.82 & 170.19 & 135.05 \\
\hline & S/OPN & 270.58 & 207.50 & 163.31 \\
\hline \multirow{8}{*}{$k=4$} & EDD & 285.58 & 108.70 & 68.91 \\
\hline & MDD & 148.82 & 99.70 & 55.31 \\
\hline & SLK & 281.11 & 124.49 & 91.36 \\
\hline & ODD & 165.33 & 62.55 & 40.69 \\
\hline & MOD & 103.23 & 37.25 & 23.11 \\
\hline & OST & 171.21 & 87.09 & 45.11 \\
\hline & $\mathrm{A} / \mathrm{OPN}$ & 270.52 & 91.25 & 61.91 \\
\hline & S/OPN & 234.23 & 100.44 & 66.25 \\
\hline \multirow{8}{*}{$\mathrm{k}=5$} & EDD & 167.93 & 65.00 & 35.24 \\
\hline & MDD & 145.51 & 56.11 & 34.21 \\
\hline & SLK & 253.58 & 78.01 & 37.23 \\
\hline & ODD & 107.46 & 31.08 & 16.33 \\
\hline & MOD & 71.29 & 28.26 & 14,66 \\
\hline & OST & 133.66 & 37.03 & 23.31 \\
\hline & $\mathrm{A} / \mathrm{OPN}$ & 124.09 & 48.27 & 35.19 \\
\hline & S/OPN & 144.22 & 65.17 & 37.36 \\
\hline \multirow{8}{*}{$k=6$} & EDD & 155.79 & 57.03 & 15.71 \\
\hline & MDD & 114.94 & 41.70 & 17.29 \\
\hline & SLK & 80.34 & 46.70 & 24.81 \\
\hline & ODD & 72.10 & 18.73 & 7.35 \\
\hline & MOD & 64.16 & 18.44 & 6.63 \\
\hline & OST & 103.45 & 24.50 & 8.82 \\
\hline & $\mathrm{A} / \mathrm{OPN}$ & 88.25 & 31.58 & 24.20 \\
\hline & S/OPN & 137.31 & 47.60 & 27.33 \\
\hline
\end{tabular}

In the previous FMS studies (Montazeri and Wassenhowe 1989; Choi and Malstrom 1988), slack-based rules were found to be the best rules. However these rules did not perform well in our studies. Instead, MOD is the preferable rule. This may be due to differences among the systems used and assumptions made. Also, MOD was not tested in the above studies. In our study, the objective was to model three important elements of FMSs (machines, AGVs, and finite buffer capacities) and their interactions, in detail. From this perspective, the system modeled in this study consists of machining centers which have a finite input/ouput buffer space and are tied together with an AGV system. 
This our results are very similar to those found in earlier job-shop studies (Baker 1984; Baker and Kanet 1984). However, in contrast to job-shops, some difficulties were experienced in distinguishing the relative effectiveness of the rules in a simulated FMS environment. This can be due to the following reasons: (1) a part which has the highest priority at a current station would not have the same degree of urgency at the other stations, because, in the FMS model, the part pool at any station is limited by the queue capacity; (2) a part finishing the current operation cannot be delivered immediately to the next station by the AGV system, due to another rule set (AGV rules), which is independent from the machine scheduling rules.

The results presented in this article should be interpreted with reference to the FMS modeled and to the experimental conditions described. Realizing that each FMS is custommade, there is a need for further research to develop new rules and to continue testing existing ones. Such research should also address the impact of varying system parameters, such as different layouts and AGV configurations, as well as service and demand fluctuations.

\section{References}

Baker, K.R., "Sequencing Rules and Due-Date Assignments in a Job Shop," Management Science, Vol. 30 , No. 9, pp. 1093-1104 (1984).

Baker, K.R. and Kanet, J.J., "Improved Decision Rules in a Combined System for Minimizing Job Tardiness," International Journal of Production Research, Vol. 22, No. 6, pp. $917-921$ (1984).

Baker, K.R. and Kanet, J.J., "Job Shop Scheduling with Due-Dates," Journal of Operations Management, Vol. 4, No. 1, pp. 11-22 (1983).

Choi, R.H. and Malstrom, E.M., "Evaluation of Traditional Work Scheduling Rules in a Flexible Manufacturing System with a Physical Simulator," Joumal of Manufacturing Systems, Vol. 7, No. 1, pp. 33-45 (1988).

Conway, R.W., Maxwell, W.L. and Miller, L.W., Theory of Scheduling, Reading, MA: Addison-Wesley (1967).

Conway, R.W. "Some Tactical Problems in Digital Simulation," Management Science, Vol, 10, No. 1, pp. 47-61 (1963).

Han M. and McGinnis, L.F., "Control of Material Handling Transporter in Automated Manufacturing," IIE Transactions, Vol. 21, No. 2, pp. 184-190 (1989).

Hutchinson J., Leong, K., Synder, D and Ward F., "Scheduling for Random Job Shop Flexible Manufacturing Systems," in Proceedings of the Third ORSA/TIMS Conference on Flexible Manufacturing Systems: Operations Research Models and Applications, K.E. Stecke and R. Suir (Eds.), Elsevier Science Publishers B.V., Amsterdam, pp. 161-166 (August 1989).

Kanet J.J. and Christy, D.P., "Manufacturing Systems with Forbidden Early Shipment: Implications for Setting Manufacturing Lead Times," International Journal of Production Research, Vol. 27, No. 5, pp. 783-792 (1989).

Kanet, J.J. and Hayya, J.C., "Priority Dispatching with Operation Due-Dates in a Job Shop," Journal of Operations Management, Vol. 2, No. 3, pp. 167-175 (1982).

Kusiak, A. and Chen M., "Expert Systems for Planning and Scheduling Manufacturing Systems," European Journal of Operations Research, Vol. 34, No. 3, pp. 113-130 (1988).

Kusiak, A., "Scheduling Flexible Machining and Assembly System," in Proceedings of the Second ORSA/TIMS Conference on Flexible Manufacturing Systems: Operations Research Models and Applications, K.E. Stecke and R. Suri (Eds.), Elsevier Science Publishers B.V., Amsterdam, pp. 521-526 (August 1986).

Kusiak, A., "Flexible Manufacturing Systems: A Structural Approach," International Journal of Production Research, Vol. 23, No. 6, pp. 1057-1074 (1985).

Montazeri, M. and Wassenhove L.N.V., "Analysis of Scheduling Rules for an FMS," International Joumal of Production Research, Vol. 28, No. 4, pp. 785-802 (1990).

Pegden, C.D., Introduction to SIMAN, State College, Pennsylvania: Systems Modeling Corporation (1985). 
Raman, N., Talbot, F.B. and Rachamadugu, R.V., "Simultaneous Scheduling of Machines and Material Handling Devices in Automated Manufacturing," in Proceedings of the Second ORSA/TIMS Conference on Flexible Manufacturing Systems: Operations Research Models and Applications, K.E. Stecke and R. Suri (Eds.), Elsevier Science Publishers B.V., Amsterdam, pp. 321-326 (August 1986).

Sabuncuoglu, I. and Hommertzheim, D.L. "Experimental Investigation of FMS Machine and AGV Scheduling Rules Against Mean Flow-time Criterion, International Journal of Production Research, Vol. 30, No. 7, pp. $1617-1635$ (1992a).

Sabuncuoglu, I. and Hommertzheim, D.L. "Dynamic Dispatching Algorithm for Scheduling Machines and Automated Guided Vehicles in a Flexible Manufacturing System," International Journal of Production Research, Vol. 30, No. 5, pp. 1059-1079 (1992b).

Sabuncuoglu, I. and Hommertzheim, D.L., "An Investigation of the FMS Due-Date Scheduling Problem: Evaluation of Due-Date Assignment Rules," Working Paper No. 90-02, Industrial Engineering Department, The Wichita State University, KS (1990).

Sabuncuoglu, I. and Hommertzheim, D.L., "An Investigation of Machine and AGV Scheduling Rules in an FMS," in Proceedings of the Third ORSA/TIMS Conference on Flexible Manufacturing Systems: Operations Research Models and Applications, K.E. Stecke and R. Suri (Eds.), Elsevier Science Publishers B.V., Amsterdam, pp. 261-266 (August 1989a).

Sabuncuoglu, I. and Hommertzheim, D.L., "Expert Simulation Systems: Recent Developments and Applications in Flexible Manufacturing Systems," Computers and Industrial Engineering, Vol. 16, No. 4, pp. 575-585 (1989b).

Seidmann, A. and Tenenbaum, A., "Optimal Stochastic Scheduling of Flexible Manufacturing Systems with Finite Buffers," in Proceedings of the Second ORSA/TIMS Conference on Flexible Manufacturing Systems: Operations Research Models and Applications, K.E. Stecke and R. Suri (Eds.), Elsevier Science Publishers B.V., Amsterdam, pp. 487-498 (August 1986).

Smith, M.L., Ramesh R., Dudek, R.A. and Blair, E.L., "Characteristics of U.S. Flexible Manufacturing SystemsA Survey," in Proceedings of the Second ORSA/TIMS Conference on Flexible Manufacturing Systems: Operations Research Models and Applications, K.E. Stecke and R. Suri (Eds.), Elsevier Science Publishers B.V., Amsterdam, pp. 477-486 (August 1986).

Smith, M. and Seidmann, A. "Due-Date Selection Procedures for Job Shop Simulation," Computers and Industrial Engineering, Vol. 7, No. 3, pp. 199-207 (1981).

Stecke, K.E., "Design, Planning, Scheduling, and Control Problems of Flexible Manufacturing Systems," Annals of Operations Research, Vol. 3, pp. 3-12 (1985). 